\title{
DESAFIOS NA EXECUÇÃO DO ATENDIMENTO SOCIOEDUCATIVO DE JOVENS EM PRIVAÇÃO DE LIBERDADE
}

\author{
CHALLENGES IN THE EXECUTION OF SOCIOEDUATIVE \\ ATTENDANCE OF YOUNG PEOPLE \\ IN DEPRIVATION OF LIBERTY
}

\section{DESAFÍOS EN LA EJECUCIÓN DEL SERVICIO SOCIOEDUCATIVO DE JÓVENES EN PRIVACIÓN DE LIBERTAD}

\author{
Julio Cesar Francisco \\ Elenice Maria Cammarosano Onofre \\ Universidade Federal de São Carlos
}

\begin{abstract}
Resumo O presente artigo é resultado de pesquisa de Mestrado em Educação em que se apresenta algumas dinâmicas da execução de medidas socioeducativas em unidade de internação no atendimento de jovens em privação de liberdade na cidade de Fortaleza, estado do Ceará, Brasil, e de alguns desafios do Sistema Socioeducativo. Os procedimentos metodológicos utilizados na investigação são de caráter qualitativo, na perspectiva do materialismo histórico-dialético, valendo-se da análise de conteúdo no processo de coleta, organização e análise dos dados. Os resultados da pesquisa identificam atuações na gestão do atendimento socioeducativo fragmentadas e desconexas da rede de serviços públicos, num processo de criminalização e institucionalização de jovens, por meio de paradigma tradicional e repressivo dentro da segurança pública, delegando à polícia dois fazeres: i) apreensão de populações pobres da periferia pelo cometimento de ato infracional; e ii) uso desproporcional de força violenta na contenção dos conflitos dentro de unidade de internação, em vista de harmonia, vigilância e adaptação no confinamento.

Palavras-chave: Ato infracional; Gestão do sistema socioeducativo; Jovens em PrivaÇão DE LIBERDADE.
\end{abstract}


Abstract This article is a result of a Master's Degree in Education research that presents some dynamics of the execution of socio-educational measures in a detention unit of young people in deprivation of liberty in Fortaleza, state of Ceará, Brazil, and some of the socio-educational system challenges. The methodology used qualitative procedures, in the perspective of historical-dialectical materialism, and for the process of data collection and organization was used the content analysis. The results of the research identify the practice of socio-educational management as fragmented and disjointed from the public service network, along with a criminalization and institutionalization process of young people through a traditional and repressive paradigm within public security. Was also identified basically two type of police behavior: i) apprehension of impoverished population from periphery by the committing of an infraction act; and ii) disproportionate use of force in restraining of conflicts within the detention unit, instead of harmony, vigilance and adaptation in confinement.

Key-Words: InFRACTIONARY ACT; MANAGEMENT OF THE SOCIO-EDUCATIONAL SYSTEM; Youth IN DEPRIVATION OF LIBERTY.

Resumen El presente artículo es el resultado de una investigación de Maestría en Educación en la que se presentan algunas dinámicas de la ejecución de medidas socioeducativas en unidad de internación en la atención de jóvenes en privación de libertad en la ciudad de Fortaleza, estado de Ceará, Brasil, y de algunos desafíos del Sistema Socioeducativo. Los procedimientos metodológicos utilizados en la investigación son de carácter cualitativo, en la perspectiva del materialismo histórico-dialéctico, en el que se utilizó la análisis de contenido en el proceso de recolección, organización y análisis de los datos. Los resultados de la investigación identifican actuaciones en la gestión del servicio socioeducativo fragmentados y desconexos de la red de servicios públicos, en un proceso de criminalización e institucionalización de jóvenes, a través de paradigmas tradicional y represivo dentro de la seguridad pública, delegando a la policía dos hechos: i) de poblaciones pobres de la periferia por la comisión de acto infractor; y ii) uso desproporcionado de fuerza violenta en la contención de los conflictos dentro de unidad de internación, en vista de armonía, vigilancia y adaptación en el confinamiento.

Palabras Clave: Acto infractor; Administración del sistema socioeducativo; Jóvenes en PRIVACIÓN DE LIBERTAD.

\section{INTRODUÇÃo}

O presente artigo é resultante de pesquisa de mestrado desenvolvida entre os anos 2015 e 2017, com apoio financeiro do Conselho Nacional de Desenvolvimento Científico e Tecnológico (CNPq).

Objetivou-se com o estudo analisar os desafios na execução do atendimento socioeducativo e sua (não) relação com os serviços públicos dos municípios, sobretudo de pensar na necessidade de uma ação dos agentes do Estado que atuam na Segurança Pública, que tenha 
fator pedagógico e preventivo, em vista da redução da violência e dos conflitos dentro e fora de unidades de internação.

$\mathrm{O}$ atendimento socioeducativo deve favorecer a desaprovação da conduta do autor de ato infracional, ao mesmo tempo em que oferta condições para a inclusão e integração social, em prol dos direitos universais do ser humano, como estabelecem as legislações nacionais (ECA - Estatuto da Criança e do Adolescente e SINASE - Sistema Nacional de Atendimento Socioeducativo) e também os tratados e convenções internacionais que o Brasil é signatário (FRANCISCO; MARTINS, 2017).

Todavia, o Brasil vive e reproduz uma democracia disjuntiva, pois, se por um lado as legislações viabilizaram a ampliação da institucionalização dos direitos políticos, por outro lado não representaram no cotidiano a efetivação dos direitos civis (CALDEIRA; HOLSTON, 1999), de violação das legislações e tratados assumidos, principalmente em relação aos jovens mais vulneráveis às atitudes infracionais e premidos na desigualdade, que aprofundam as manifestações de violência e o sentimento de impunidade e de medo da população.

Em vista de estratégias para o redirecionamento social de adolescentes e jovens em cumprimento de medida socioeducativa de internação, há que se ter em mente os equívocos históricos que se perpetuam nas práticas da prisão juvenil como absolutamente punitiva (PRIORI, 2006; MAUAD, 2006; PASSETTI, 2006). Para onde se está indo com o modelo de responsabilização juvenil brasileiro? Quais os seus desafios e impactos na gestão da vida? Como enfrentar com serenidade e celeridade as superlotações e as violações de direitos?

Responder a essas questões é um desafio. Na busca por respostas, não se pode deixar de considerar, como caminho de se efetivar práticas mais efetivas na execução socioeducativa, que os adolescentes, faixa etária entre 12 e 18 anos incompletos, estão em processo peculiar de desenvolvimento biopsicossocial e que, quando da constatação de um ato infracional, eles devem ser submetidos a uma medida socioeducativa (Art. 112 do ECA) que se afigurar mais adequada e que possa garantir todos os direitos fundamentais de acesso à educação, saúde, lazer, esporte, profissionalização etc. A medida de internação é a sentença socioeducativa mais rigorosa, não tem um tempo mínimo de internação, mas não pode exceder o prazo de três anos, e deve ser aplicada apenas nos casos de grave ameaça à vida e à convivência comunitária.

Tendo em vista esse quadro, apresenta-se neste artigo: i) os procedimentos metodológicos utilizados no estudo e algumas possibilidades de pesquisa em unidades de internação; ii) as mudanças de paradigma na política de atendimento ao adolescente em conflito com a lei com o advento do ECA e da Lei do SINASE, respaldadas pela Constituição Federal de 1988 no seu Artigo 227; iii) problemáticas nas unidades de internação na região de Fortaleza; iv) aspectos que conformam e reproduzem a violência institucionalizada sobre os adolescentes; e, v) por fim, apontam-se algumas considerações, à guisa de considerações finais. 


\section{Procedimentos metodológicos: desafios do fazer PesQuisa em UNIDAde DE INTERNAÇÃo}

Do ponto de vista metodológico, é importante consignar que a pesquisa foi sustentada por uma abordagem qualitativa (CROSWELL, 2007; BOGDAN; BIKLEN, 2010; LÜDKE; ANDRÉ, 2012), na perspectiva materialista histórico-dialética, utilizando-se o método de análise de conteúdo de Bardin (2010) no processo científico, em que se ouviram 12 socioeducadores e contou com visitas in loco na unidade de internação, entre os meses de janeiro e junho de 2016.

Por se tratar de abordagem de natureza qualitativa, buscou-se destacar a relevância social da pesquisa, o seu impacto na busca de resoluções (CHIZZOTTI, 2000; LÜDKE; ANDRÉ, 2012), e algumas proposições com o intuito de colaborar com os processos socioeducativos no atendimento de jovens em privação de liberdade.

Os dados foram organizados a partir da "exploração de material" (BARDIN, 2010, p. 121), e se utilizou da técnica de entrevista, com destaque para as falas dos socioeducadores. ${ }^{1}$

A organização do material foi um momento longo e trabalhoso, dedicado à codificação e categorização, pois significa trabalhar com os dados brutos, transformando-os em representação do conteúdo obtido (BARDIN, 2010), agrupados em unidades de registro, a partir da noção de tema.

O tema, enquanto unidade de registro, corresponde a uma regra de recorte (do
sentido e não da forma), visto que o recorte depende do nível de análise e não
de manifestações formais reguladas. [...] geralmente utilizado [...] para estudar
motivações de opiniões, de atitudes, de valores, de crenças, de tendências, etc.
As respostas a questões abertas, as entrevistas (não diretivas ou mais estrutura-
das) individuais ou de grupo [...] podem ser, e são frequentemente, analisados
tendo o tema por base (BARDIN, 2010, p. 131).

Os temas integram parte de um grupo de elementos (unidade de registro), que são agrupados tendo em vista características comuns entre si, que fazem parte do processo de categorização das mensagens. A categorização pode ser entendida como uma operação de classificação dessas mensagens e comporta duas etapas fundamentais: o inventário, que é isolar os elementos; e, posteriormente, a classificação propriamente dita, "repartir os elementos, e [...] impor uma certa organização às mensagens" (BARDIN, 2010, p. 146).

Assim, considerou-se como categorias de análise: o fluxo de atendimento socioeducativo, a relação de ensino entre socioeducador e os jovens, as expectativas de convivência, os espaços e os sujeitos de poder (segurança pública, numa atuação policialesca, direção, alas de convivência, celas-dormitórios, as regras dos jovens), uma caracterização do espaço físico (cuja localização da unidade é representada em mapa gerado por técnicas de geoprocessamento no software Arcgis 10.1), a organização do uso do tempo, o perfil social,

1 "Entende-se por socioeducador o profissional responsável pela execução de medidas socioeducativas" (FRANCISCO; MARTINS, 2017, p. 295), no presente caso, os agentes de apoio que trabalham nas alas da unidade. 
econômico, etário e escolar dos socioeducadores, e os conflitos na convivência. Essas categorias permitiram produzir um retrato da unidade de internação e os seus desafios para a segurança pública e para o atendimento socioeducativo.

Vale destacar que a pesquisa em contexto de medidas socioeducativas de internação tem se mostrado um desafio, decorrente do cuidado e receio de gestores de Estado na interferência de pesquisadores no trabalho que se pretende realizar. Esse entrave para acessar o campo tem causado dificuldades para a produção de conhecimento nessa temática, que corresponde às relações de força intrínsecas que limitam ou possibilitam a compreensão do espaço social pouco estudado: as unidades de internação.

A negativa de acesso a esse tipo de pesquisa é recorrente, por exemplo, na política do governo do PSDB (Partido da Social Democracia Brasileira) no estado de São Paulo, justamente o estado em que há o maior número de unidades do Brasil (mais de 150 unidades e o maior número de jovens internados). Muitas dessas unidades têm potencial para desenvolver estratégias inovadoras para a execução do atendimento de jovens, para além do viés repressivo e disciplinador da segurança pública, como também fomentar parcerias entre Estado e município para um processo gradativo de desinstitucionalização e integração dos inimputáveis nos espaços públicos da cidade.

Tendo em vista o quadro de necessidade e anseio de pesquisadores na produção de conhecimento em socioeducação, insta destacar alguns caminhos e possibilidades para a realização de trabalho de campo no regime fechado.

Um dos problemas que se pode ter é a dificuldade de autorização para conduzir o estudo que foi planejado, em geral, por meio de um projeto de pesquisa preliminar. Nesse caso, ser objetivo como pesquisador, apresentar a intencionalidade, as justificativas e os métodos da coleta de dados é importante para reduzir as chances de indeferimento, que dependerá, normalmente, da disponibilidade e interesse das instituições.

Mesmo com toda a cautela e com projetos bem estruturados, nem sempre, em uma única vez, obtém-se sucesso. Mesmo com a negativa, faz-se necessário buscar alternativas de acesso ao campo. Pode-se recorrer a outros sujeitos em outra territorialidade, mas que compartilham de características semelhantes, necessárias e pertinentes ao tema de estudo.

A persistência, flexibilidade, criatividade e a disposição para novos desafios são características fundamentais no perfil dos pesquisadores, assim como, o trabalho em regime de colaboração com outros profissionais mais experientes.

O pedido de autorização para a realização de pesquisa pode ser um processo moroso, que se alonga por meses, entre o momento do pedido e o do parecer. Assim, quando se trata de estudo de mestrado, que o tempo é demasiado curto, é mais do que pertinente já no primeiro semestre ou, no mais tardar, no segundo semestre de ingresso, que o proponente tenha um projeto bem elaborado para submissão da pesquisa aos órgãos avaliadores: os responsáveis pelas medidas socioeducativas de internação.

Para não atrasar a pesquisa ou correr o risco de ficar sem "sujeitos-participantes do estudo", seja no doutorado, seja no mestrado, é sensato, o quanto antes, realizar o levantamento de documentos para a submissão da proposta de pesquisa. 
Em geral, cada Estado tem representantes responsáveis especificamente para avaliar e deliberar sobre os projetos, os quais se propõem a ajudar na formatação da proposta, tendo em vista as exigências e especificidades de cada contexto. Em alguns lugares essa etapa é mais formal, enquanto que em outros o processo é menos burocrático e mais receptível.

Nesses casos de maior flexibilidade, dadas as devidas proporções, os gestores buscam alternativas mais eficientes para o trabalho com jovens em conflito com a lei, tendo em vista a redução das infrações e, até mesmo, nos casos mais graves, de evitar a instabilidade nas próprias instituições, que causam rebeliões e danos para o próprio interno, assim como, para familiares, funcionários, Estado e sociedade de modo geral. Essa era a realidade do governo do estado do Ceará, no período deste estudo, que buscava pela redução das infrações e violências, o que facilitou a inserção no campo de pesquisa.

Uma maneira de garantir maior grau de proximidade com o campo é oferecer apoio aos gestores e aos profissionais. Poderia, inclusive, firmar-se uma parceria de estágio, paralelo ao trabalho de campo, com observações e participações naquilo que se pretende conhecer e compreender.

Passado esse processo de submissão, e com a autorização em mãos, os obstáculos serão menores, podendo começar o trabalho de pesquisa com empenho? Nem sempre. Muitas outras dificuldades surgirão e erros poderão ser cometidos, os quais servirão como aprendizagem e, mantendo a confiança, a pesquisa poderá ser realizada a contento. Vale uma ressalva: se o pesquisador tem medo, não consegue lidar com erros, se sentir-se atrapalhado, sem funcionalidade, que não está preparado psicologicamente para enfrentar um ambiente de privação de liberdade, deve-se procurar apoio e orientação aos que possuem uma prática vivida nesses espaços e conhecem as regras e as rotinas.

Outras considerações para os primeiros dias no campo de investigação podem ajudar. No início, é preciso conhecer as regras do ambiente, aquilo que pode ou não pode ser feito, por se tratar de um espaço que tem a preocupação com a segurança e a vigilância. Essa vigilância institucional legitima, quando feita de modo exacerbada, a conservação de um estilo de vida infracional, que corresponde a características da contínua desconfiança e que tende a reduzir as chances de mudança do atendido. O que se faz é uma reprodução do infrator, porém de maneira controlada.

Com as experiências adquiridas e regras assimiladas, o pesquisador vai se identificando com o processo de observação e participação no campo. A confiança aumenta pela prática de estar in loco, num engajamento de aprender e colaborar com o processo de responsabilização socioeducativa.

A realidade nesses espaços fechados e muitas vezes nebuloso e desconhecido vai se constituindo um ser pesquisador com características singulares. Essa tarefa é difícil e pode causar ansiedades, especialmente, pelas limitações que tem o pesquisador quando pretende colaborar com mudanças na rotina da instituição. Tanto eles, atendidos e profissionais da unidade, quanto os pesquisadores, acabam se habituando no convívio diário. 


\section{As mudanças de paradigma na política de ATENDimento aO ADOLESCEnTE EM CONFLITO COM A LEI}

A história da política de atendimento às crianças e aos adolescentes vulneráveis e em situação de conflito com a lei remete concretamente à reprodução das concepções e das práticas autoritárias, num quadro de política higienista e de educação repressiva. Processo esse que marcou o século XX no Brasil e que, como se verá mais adiante por meio das análises da coleta dos dados, se percebe uma reiteração de um habitus controlador dos profissionais responsáveis pela execução da medida socioeducativa de internação no Ceará. Fatores esses que têm aumentado as infrações e as sentenças privativas de liberdade.

Embora se tenha como referência o Estatuto da Criança e do Adolescente - ECA e o Sistema Nacional de Atendimento Socioeducativo - SINASE (Lei 12.595/2012) no atendimento socioeducativo, ainda impera a lógica da Doutrina do Direito do Menor, em que esta se ancorava na ideologia que criminalizava a pobreza, como "menores" sem direitos de uma vida diferente daquela dos atos infracionais (PEREZ; PASSONE, 2010). Tanto é que, como forma de distinção, adota-se ainda hoje, 27 anos após ECA, estratégias de responsabilização socioeducativa sem considerar a participação comunitária e, em muitos casos, longe da família, sobretudo quando há unidades concentradas nas capitais, como é o caso de Fortaleza.

Vale revisitar algumas bases que fundamentam a repressiva política ao adolescente no Brasil e seus desafios atuais.

Em 1927 se deu a criação do primeiro Código de Menores Mello Matos, pelo Decreto $\mathrm{n}^{\mathrm{o}}$. 17.943-A, o qual regulou o atendimento de todos os indivíduos, homens ou mulheres, fixando a imputabilidade aos 18 anos de idade (FRONTANA, 1999; PEREZ; PASSONE, 2010).

Entre as principais estratégias criadas no Brasil para controlar a violência dos inimputáveis, vale destacar também a criação do Serviço de Assistência ao Menor - SAM e da Fundação Estadual do Bem-Estar do Menor - FEBEM (PEREZ; PASSONE, 2010).

Em 1941, no regime de Getúlio Vargas, o SAM, vinculado ao Ministério da Justiça, tinha uma política de atendimento educativo que residia na ideia da institucionalização dos menores para corrigi-los e reeducá-los, tendo em vista a mudança de valores e ações que pudessem desenvolver nestes a harmonia e a adaptação positiva no convívio (LIBERATI, 2012). O SAM ficou conhecido por suas práticas de atendimento violento e disciplinador, de caráter policial e punitivo, o que inviabilizou qualquer tipo de atuação pautada em mecanismos de proteção e de convivência educativa adequada (FALEIROS, 2004).

Por ocasião do golpe empresarial-militar, que convergia para a criação de um anteprojeto de extinção do SAM, o governo federal tomou a frente e elaborou algumas proposições destinadas para essa população. Entre as políticas mais relevantes desse governo pode-se destacar a promulgação da Política Nacional do Bem-Estar do Menor - PNBEM, pela Lei $\mathrm{n}^{\circ}$. 4.513, de $1^{\circ}$. de dezembro de 1964 (BECHER, 2011; MASELA, 2010).

Em consonância com a filosofia da época, criou-se a Fundação Nacional do Bem-Estar do Menor - FUNABEM, instância normativa, a qual tinha por finalidade a execução do PNBEM (PEREZ; PASSONE, 2010). 
A FUNABEM assumiu a função de formuladora de políticas de atendimento ao menor expressa no PNBEM e se tornou o órgão responsável pela implantação das entidades executoras (FEBEM). Embora caibam várias ressalvas, esse momento histórico foi preparando o terreno para a estrutura socioeducativa no território nacional.

A ideologia de atendimento ao menor nos moldes do regime civil-militar ganhou força de Lei pelo Código de Menores, Lei no ${ }^{\circ}$ 6.697/79, que se dizia um instrumento de proteção aos excluídos com idade abaixo de 18 anos, o que ajudou a consolidar o processo histórico de ordem e estabilidade (BECHER, 2011), por meio da institucionalização do "menor irregular”. Essa lei, a propósito, substitui o Código Mello Matos de 1927 (MASELLA, 2010, p. 24).

O processo de criação do PNBEM e, por conseguinte, a implantação e o funcionamento da FEBEM se deram de maneira repressiva, violenta. Os mecanismos operantes se pautavam na criminalização e na naturalização da criança e do adolescente pobre, em que esses eram ausentes de direitos básicos (IANNI, 1992; LANCELOTTI, 1987). Esse modelo inadequado de estrutura vai dar lugar à concepção de socioeducação. Socioeducação essa a que estamos mais habituados, a partir do ECA e mais especificamente da lei do SINASE, compreendendo-a enquanto Sistema integrado de atuação institucional e intersetorial, de engajamento humanizado. Aspectos esses em que o primeiro autor tratará em tese de doutoramento.

Destarte, em vista de superar a história de atendimento ao autor de ato infracional e lhe conferir uma sentença mais adequada, pode-se sinalizar a importância da promulgação do ECA, da Lei do SINASE, e da Constituição da República Federativa do Brasil (CF/1988), pois são as leis que consolidaram a proteção integral da criança e do adolescente, em substituição ao Código de Menores de 1979.

No ECA, reitera-se, o adolescente é a pessoa de faixa etária entre 12 e 18 anos incompletos e, quando da autoria de alguma infração, não é tido como criminoso, mas em situação de envolvimento com ato infracional (PEREZ; PASSONE, 2010), cabendo uma medida socioeducativa em seu benefício.

A Constituição respalda esse caráter protetivo no seu Artigo 227:

É dever da família, da sociedade e do Estado assegurar à criança, ao adolescente e ao jovem, com absoluta prioridade, o direito à vida, à saúde, à alimentação, à educação, ao lazer, à profissionalização, à cultura, à dignidade, ao respeito, à liberdade e à convivência familiar e comunitária, além de colocá-los a salvo de toda forma de negligência, discriminação, exploração, violência, crueldade e opressão. (Redação dada pela Emenda Constitucional nº. 65, de 2010) (BRASIL, 1998.)

Vale ainda considerar:

$\S 3^{\circ}$. O direito a proteção especial abrangerá os seguintes aspectos:

I - idade mínima de quatorze anos para admissão ao trabalho, observado o disposto no art. $7^{\circ}$., XXXIII;

II - garantia de direitos previdenciários e trabalhistas; 
III - garantia de acesso do trabalhador adolescente e jovem à escola; (Redação dada pela Emenda Constitucional nº. 65, de 2010)

IV - garantia de pleno e formal conhecimento da atribuição de ato infracional, igualdade na relação processual e defesa técnica por profissional habilitado, segundo dispuser a legislação tutelar específica;

$\mathrm{V}$ - obediência aos princípios de brevidade, excepcionalidade e respeito à condição peculiar de pessoa em desenvolvimento, quando da aplicação de qualquer medida privativa da liberdade;

VI - estímulo do Poder Público, através de assistência jurídica, incentivos fiscais e subsídios, nos termos da lei, ao acolhimento, sob a forma de guarda, de criança ou adolescente órfão ou abandonado;

VII - programas de prevenção e atendimento especializado à criança, ao adolescente e ao jovem dependente de entorpecentes e drogas afins. (Redação dada pela Emenda Constitucional no. 65, de 2010) (BRASIL, 1988.)

Esses novos paradigmas jurídicos ressignificaram a compreensão do modo de conceber e lidar com os adolescentes que se envolvem com atos infracionais (PEREZ; PASSONE, 2010). Esses indivíduos são compreendidos como pessoas que estão num momento de formação e de desenvolvimento de suas potencialidades. Em razão disso, lhes é assegurado de modo especial uma proteção integral, enquanto sujeitos de direitos, além de prever que eles não sofram discriminação, crueldade e opressão dentro ou fora das medidas socioeducativas. Medidas essas previstas no Artigo 112 do ECA (BRASIL, 1990).

A Lei 12.594/2012 institui, em seu Artigo 1ํ, o Sistema Nacional de Atendimento Socioeducativo (SINASE) e regulamenta a execução das medidas socioeducativas (BRASIL, 2012), que têm por objetivo:

I - a responsabilização do adolescente quanto às consequências lesivas do ato infracional, sempre que possível incentivando a sua reparação;

II - a integração social do adolescente e a garantia de seus direitos individuais e sociais, por meio do cumprimento de seu plano individual de atendimento; e III - a desaprovação da conduta infracional, efetivando as disposições da sentença como parâmetro máximo de privação de liberdade ou restrição de direitos, observados os limites previstos em lei.

$\S 3$ - Entende-se por programa de atendimento a organização e o funcionamento, por unidade, das condições necessárias para o cumprimento das medidas socioeducativas.

$\S 4^{\circ}$ Entende-se por unidade a base física necessária para a organização e o funcionamento de programa de atendimento (BRASIL, 2012).

No que diz respeito à integração do Sistema:

Artigo 2o O Sinase será coordenado pela União e integrado pelos sistemas estaduais, distrital e municipais, responsáveis pela implementação dos seus respectivos programas de atendimento a adolescente ao qual seja aplicada medida socioeducativa, com liberdade de organização e funcionamento, respeitados os termos desta Lei (BRASIL, 2012). 
Embora haja todo um aparelho de Estado, desde o nacional até o municipal, cada qual com as suas competências previstas nos Artigos $3^{\circ}$. ao $5^{\circ}$. (BRASIL, 2012), integrado às instituições do Ministério Público, Poder Judiciário, Defensoria Pública e Segurança Pública que fazem o atendimento inicial ao adolescente envolvido e acusado com determinada infração, quando da constatação da autoria e sentença ao cumprimento de uma medida que se afigurar mais adequada pela autoridade judiciária competente, faz-se necessário considerar os pressupostos legais de acesso à comunidade e a responsabilidade da família e da rede de serviços dos municípios para a integração social, observando, com equipe especializada, as reais condições de um cumprimento socioeducativo mais flexível ou restritivo, mesmo quando da privação da liberdade. Disso depende o êxito do funcionamento interinstitucional e intersetorial do Sistema Socioeducativo, corroborando com a execução da medida socioeducativa em consonância com o Artigo 227 da Constituição Federal.

Todavia, como se observa na realidade do estado do Ceará, há muitos desafios para fazer valer uma adequada responsabilização socioeducativa, em vista de diversas problemáticas, acompanhadas e fiscalizadas pelo Conselho Nacional dos Direitos da Criança e do Adolescente - CONANDA, nos termos previstos na Lei 8.242/1991.

Há muitas instituições, programas, redes de apoio, movimentos sociais próximos ao Sistema Socioeducativo, em vista de superar as violações de direitos, que se revelam desafiadoras aos que entendem a necessidade de humanizar o atendimento socioeducativo, valorizando a participação comunitária e as oportunidades de experiências educativas que possam redirecionar as ações dos adolescentes e dos jovens, não apenas porque eles precisam, mas porque é exigência de uma sociabilidade mais justa e pacífica.

\section{Problemáticas em unidade de internaÇão na região de Fortaleza-CE}

A unidade de internação e suas relações socioeducativas, desde o primeiro contato, que ocorreu no dia 13.01.2016, mostrou-se complexa, em seus mais variados espaços e tempos, da gestão, coordenação de disciplina e coordenação pedagógica até o trabalho educativo realizado com os jovens e dos procedimentos da segurança, que operam de maneira inter-relacionadas. Segurança e controle funcionam atrelados aos procedimentos educativos escolares e não escolares.

Em meio à complexidade da instituição, a preocupação inicial que se teve foi buscar subsídios para entender o itinerário do trabalho, por meio de uma relação colaborativa com gestores, funcionários da coordenação pedagógica, socioeducadores, psicologia, assistência social e departamento jurídico.

A equipe de funcionários viabilizou o acesso irrestrito aos espaços, aos jovens, aos processos judiciais, aos documentos oficiais da unidade, e tudo que fosse necessário para o desenvolvimento deste estudo. O acesso permitiu conhecer as dificuldades que têm aprofundado as violências nessa região do país e, por conseguinte, os seus impactos na educação dentro das unidades, como se percebe na construção dos dados que se seguem.

Há no itinerário da medida socioeducativa uma rotina prisional, conduzida, desde a 
apreensão policial no atendimento inicial até efetivamente a sentença de privação de liberdade, que produz anseios e medos, respaldados por uma prática com excessivos procedimentos de contenção dos jovens em celas-dormitórios (CEDECA, 2016).

Os discursos e as práticas dos socioeducadores eram o de evitar violência, rebeliões, brigas e conflitos, por meio do isolamento e da vigilância dos atendidos.

Em decorrência das violações de direitos, o sistema socioeducativo do Ceará se deteriorou e, como consequência, denunciado constantemente nos meios de comunicação de massa, pressionados por órgãos nacionais e internacionais, com destaque para a Comissão Interamericana dos Direitos Humanos, assim como pela Associação Nacional dos Centros de Defesa de Direitos de Crianças e Adolescentes - ANCED. Tal situação provocou, inclusive, o acompanhamento mais próximo por parte da Secretaria dos Direitos Humanos da Presidência da República² e outras instâncias do Governo Federal (CEDECA, 2016).

A instabilidade no sistema socioeducativo de internação do Ceará resultou ainda em diversas inspeções nas unidades, que foram realizadas, entre outros, pelo Fórum Permanente das Organizações Não Governamentais de Defesa dos Direitos de Crianças e Adolescentes do Ceará - Fórum DCA e pelo Centro de Defesa da Criança e do Adolescente do Ceará - CEDECA, constatando os maus-tratos. As inspeções geraram um relatório em que descrevem essas violações, descumprimentos das normativas preconizadas no ECA e na Lei do SINASE, bem como, dos desafios a serem enfrentados para a superação do modelo repressivo (CEDECA, 2016).

A cultura prisional, que perpassa o sistema, está inter-relacionada com uma dinâmica histórica dentro das unidades socioeducativas, que herdada do SAM e da antiga FEBEM, se perpetua até os dias atuais e explica as ações de caráter repressivo, mais do que de caráter sociopedagógico planejado, como proposto pelos relatores do ECA no âmbito da política socioeducativa brasileira.

Tem-se uma cultura de punição e receio de atitudes violentas dentro da unidade, haja vista a vida pregressa dos atendidos, com histórico de envolvimento com o tráfico, com roubo e um significativo percentual de homicídios ( $23 \%$ dos jovens do Estado que estão privados de liberdade), sendo o último um dos maiores do Brasil, reflexo sobretudo, de uma cultura de violência social, da banalização da violência, de desigualdades socioeconômicas, de ausência de proteção social, jurídica, educativa, familiar etc.

A história de vida dos jovens, descrita em seus processos judiciais, é marcada pela restrição de acesso à rede de serviços públicos, e com vivências de evasão escolar, repetências, estruturação familiar desorganizada (muitos moravam com tios e avós) e baixa renda. Situações essas semelhantes com outras realidades do país (FRANCISCO; MARTINS, 2014; SILVA; SANTOS; MELO, 2016; FONSECA, 2013). Serviços esses, atrelados ao fator protetivo da família, que poderiam prevenir infrações ao favorecerem a integração social com caráter formativo comunitário.

2 Vale esclarecer que a SDH/PR (atualmente, no governo Michel Temer, ganhou status de Ministério dos Direitos Humanos), bem como o Itamarati, não denunciam o Estado, mas face às denúncias, sobretudo aquela internacional, passam a acompanhar toda a situação de caos, tendo em vista que quem é denunciado junto à Corte Interamericana não é o Estado do Ceará, mas sim o Estado Brasileiro. 
Essa problemática, de caráter social amplo, é de responsabilidade do Estado e enseja compromisso social de toda a sociedade: de instituições como o Poder Judiciário, o Ministério Público, a Segurança Pública, a Defensoria Pública, as políticas setoriais sob a responsabilidade de execução do governo nas três esferas, do poder legislativo, da sociedade civil, dos jovens e suas famílias (BRASIL, 1990; LIMA, 2013).

\section{A UNIDAdE DE INTERNAÇão E A VIOLÊNCIA INSTITUCIONALIZADA - PERSPECTIVAS E desafios PARA O ESTAdo do CEARÁ}

Ao longo do trabalho de coleta de dados no campo de pesquisa, pode-se visualizar e significar o contexto problemático e frágil da medida socioeducativa de internação. Este se mostrou um inadequado atendimento aos jovens, bem como, situações de funcionamento que causaram rebeliões, a destruição das estruturas físicas, as tentativas de fugas e os confrontos, resultados também da superlotação e da precarização do trabalho dos funcionários, sobretudo de socioeducadores, que atuam no contexto educativo não escolar sem possuírem perfil e formação profissional para tanto, conforme apresentado na Tabela 1.

Tabela 1 - Perfil dos socioeducadores da Unidade de Internação.

\begin{tabular}{|c|c|}
\hline Média da Renda Per Capita & $R \$ 839,69$ \\
\hline Gênero & Homens $(75 \%)$ \\
\hline \multirow{4}{*}{ Formação escolar } & Ensino Fundamental Completo $(16,67 \%)$ \\
\hline & Ensino Médio Completo $(58,33 \%)$ \\
\hline & Ensino Superior Incompleto $(16,67 \%)$ \\
\hline & Ensino Superior Completo $(8,33 \%)$ \\
\hline Média etária & 38,17 anos \\
\hline \multirow{11}{*}{ Perfil profissional } & Vigilante $(16,67 \%)$ \\
\hline & Segurança $(8,33 \%)$ \\
\hline & Serviços Gerais $(8,33 \%)$ \\
\hline & Aux. administrativo $(8,33 \%)$ \\
\hline & Garçom $(8,33 \%)$ \\
\hline & Socioeducador $(8,33 \%)$ \\
\hline & Jardineiro $(8,33 \%)$ \\
\hline & Costureiro $(8,33 \%)$ \\
\hline & Monitor de Unidade $(8,33 \%)$ \\
\hline & Músico $(8,33 \%)$ \\
\hline & Professor $(8,33 \%)$ \\
\hline
\end{tabular}

Fonte: Dados produzidos pelos pesquisadores por meio da coleta de dados realizada, 2017. 
Cultiva-se, em grande parte dos funcionários, discursos pessimistas e negativos, com elevada desconfiança em relação aos adolescentes, centrados na ideia de que, se colocados para atividades socioeducativas, haveria motins, rebeliões e fugas.

Fala 1 - Socioeducador: [...] não pode soltar esse povo agora, eles tomam a unidade.

Fala 2 - Socioeducador: [...] Rapaz, esses meninos são terriveis, você não pode descer agora, eles estão tacando pedra e cuspindo nos Socioeducadores.

Fala 3 - Pedagogo: [...] não tem atividade nesse início de ano, o ambiente está difícil de controlar [...] muitos deles são perigosos e já até mataram.

Fala 4 - Socioeducador: Os meninos são "de lua", do nada eles tumultuam a unidade.

Fala 5 - Enfermeira: Eu vou atender os jovens que estão passando mal, muitas vezes, dentro da própria ala. [...] eu tenho medo, alguns são bons, mas tem outros que intimidam, prefiro atender na minha sala, individualmente e acompanhada do Socioeducador responsável.

Fala 6 - Socioeducador: [...] os meninos têm criatividade. Se focado para o bem, poderia sair de dentro da unidade vários Isaac Newton, Albert Einstein [...]. Eu sou Socioeducadora, responsável pela vistoria dos materiais que chegam na unidade, entregues pelas famílias [...]. Minha formação é de matemática e pretendo realizar mestrado na mesma área pela UFC [Universidade Federal do Ceará]. [...] se eu poderia ensinar eles? [...] eu não tenho coragem de entrar numa sala e dar um lápis para eles (risos). O lápis pode virar uma arma e ocasionar até uma rebelião. Nunca se sabe quem eles pegariam para fugir. Eu tenho muito receio, ainda mais na atual situação de instabilidade.

Fala 7 - Socioeducador: Para realizar qualquer tipo de atividade de esporte no ambiente da quadra é preciso de pelo menos um Socioeducador para cada dois internos. [...]. Nós estamos com aproximadamente 95 jovens e apenas 10 Socioeducadores para a unidade toda, [...] então é impossivel pensar em realizar esporte com eles, pois pode ocorrer outra rebelião. [...]. Para realizar atividade é preciso de segurança, saber que ninguém será feito refém. [...] Os Socioeducadores têm que tomar conta das portarias, acompanhar os jovens em médico, assistência social, enfermagem, visitas de familiares, além de ajudar na parte pedagógica, e com apenas 10 de plantão é impossivel fazer a unidade funcionar bem.

Fala 8 - Socioeducador: Tem gente que está querendo tratar esses bandidos como se fossem crianças, tem que entender que eles estão presos, cometeram crimes, e a gente não pode dar confiança.

Fala 9 - Socioeducador: Eles não são amigos de ninguém, não chegue muito perto deles, eles podem te pegar como refém, e também evite de tocar neles, muitos têm doença de pele.

Fala 10 - Socioeducador: A gente tem que garantir a segurança dos nossos funcionários, na primeira oportunidade que eles (jovens) tiverem, pode ter certeza, eles vão virar essa casa. Você tem esse discurso de confiança neles porque ainda não conhece.

Fala 11 - Socioeducador: [...] a gente não pode tratar eles como se fossem crianças, [...] eles já mataram, roubaram, são bandidos, estão aqui para pagar o que fizeram de errado para a sociedade. [...] Alguns até são mais tranquilos, mas a maioria não tem jeito não. Não fique muito perto das grades, eles podem pegar você pelo pescoço, bater, dar choque, não confie neles. Eles não são seus amigos. 
Esses discursos são frequentes nos espaços da unidade e revelam que não é possível realizar atividades fora das celas-dormitórios, haja vista a "maldade dos jovens". Disseminam-se ideias de insegurança, perigo, violência, como justificativa para efetivar um modelo repressivo como fundamento educativo.

Esse é um fator preocupante, quando se pensa na humanização do atendimento socioeducativo. O sujeito em processo educativo, como pressuposto da participação nos rumos e elaboração de projetos de vida para além da sua trajetória de envolvimento com o crime, precisa, mais do que ninguém, desenvolver autonomia e protagonismo, construídos a partir de atividades educativas em vista da liberdade, e não recolhidos/isolados em celas-dormitórios.

A administração dos conflitos é realizada principalmente pela gestão do Sistema Socioeducativo, encargo do Estado, e direção da unidade de internação que não têm dado respostas efetivas para enfrentar o problema, e se nota deficiências em recursos humanos, materiais e financeiros, o que inviabiliza a organização e a efetividade do atendimento socioeducativo destinado aos adolescentes e jovens (CEDECA, 2016).

A situação é agravada pelas superlotações (Figura 1), que é característico das diversas unidades socioeducativas da capital (Fortaleza). Faz exceção o Centro Educacional Passaré que não teve superlotação quando da coleta de dados, pois é um Centro destinado à internação provisória, num perfil de 12 a 15 anos de idade, faixa etária essa com menor incidência de jovens. A maior faixa de jovens envolvidos com a prática de ato infracional se dá a partir dos 16 anos e com maior concentração naquela de 17 anos.

A figura 1, a seguir, permite visualizar um panorama da execução das medidas socioeducativas. $^{3}$

A quantidade excessiva de internos ${ }^{4}$ dificulta a dinâmica educativa dentro da unidade, principalmente pela escassez de recursos materiais para o atendimento. Pode-se também observar que tal situação fortalece a tese da necessidade de grande "precaução", o que significa segurança quase que exclusivamente repressiva. Tais tendências causam um efeito contrário ao que se espera da socioeducação: produção de manifestações de violência, confrontos.

Insta frisar que a postura do Poder Judiciário em alguns casos, corroborada com uma atuação nem sempre adequada da Defensoria Pública e do Ministério Público, tem resultado na aplicação excessiva da medida de internação. A atuação interinstitucional do Sistema Socioeducativo tem grande responsabilidade para o redirecionamento social dos jovens e, nesse sentido, necessitam levar em consideração as reais condições de se efetivar um processo de responsabilização socioeducativa via unidade de internação.

\footnotetext{
A Vice-governadoria do estado do Ceará, desde janeiro de 2016, acompanha a situação das unidades a partir da sua responsabilidade na coordenação do "Programa Ceará Pacífico". Em vista da construção de um novo modelo de gestão para o sistema socioeducativo, por meio do Decreto 31.892 de 23/02/2016. A Vice-governadoria, ainda por meio de sua Equipe de TI (Tecnologia da Informação), a partir do Sistema Geral de Informação (SGI), desenvolveu um Sistema de Informação chamado "Socioboard", que a partir dos dados lançados no SGI, fornece relatórios e gráficos para auxiliar nas análises para a melhoria na gestão do sistema socioeducativo do Ceará.

4 O número de internos varia muito, de um dia para o outro. Diariamente são sentenciados e, ao mesmo tempo, extinta a medida socioeducativa de vários jovens. A quantidade de jovens dentro da unidade é, portanto, relativa, e o quantitativo apresentado se refere ao dia 14.01.2016.
} 


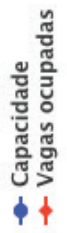

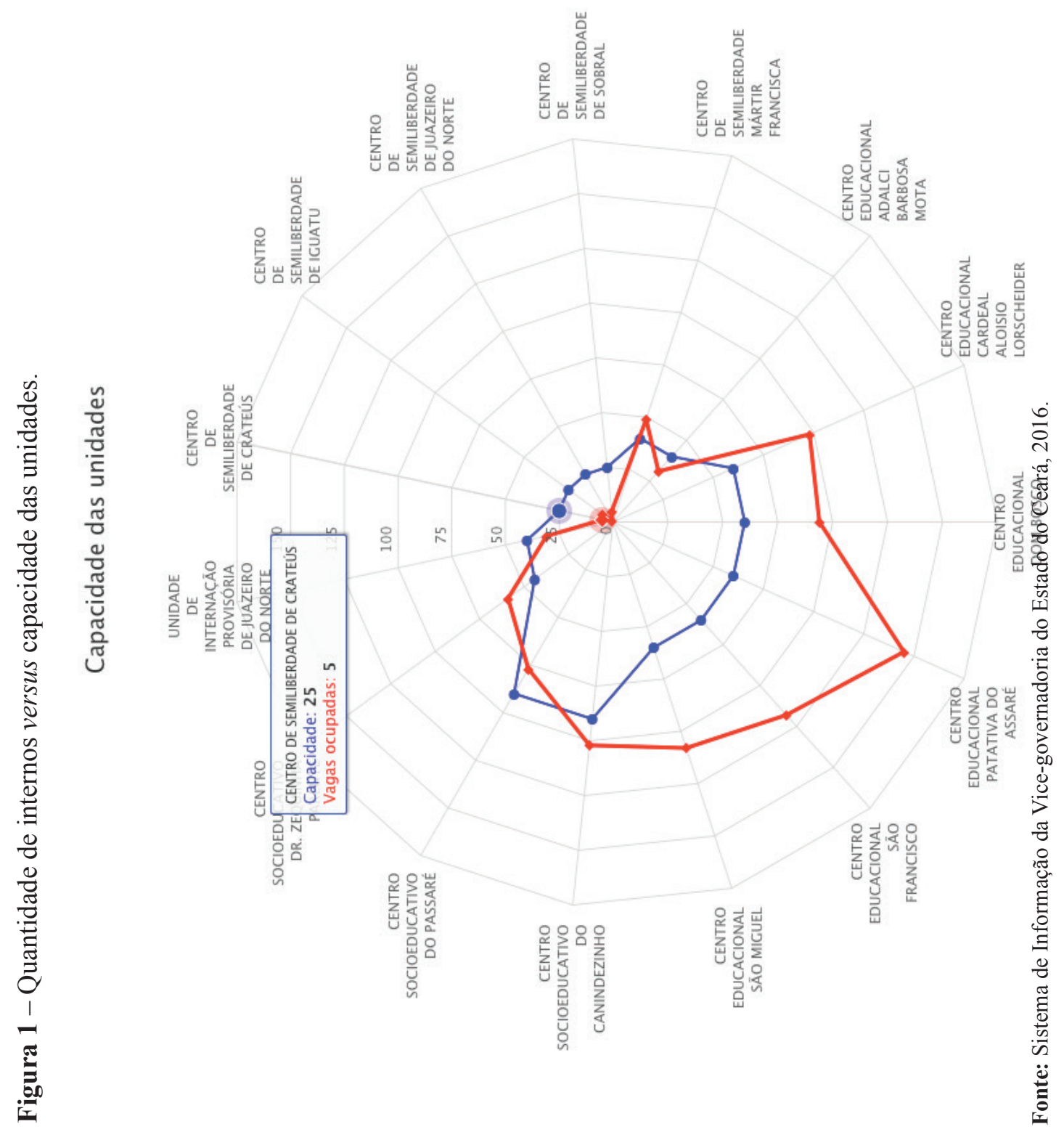


A utilização de tal medida como forma de castigo temporário ou ainda como mecanismo de proteção ${ }^{5}$ do adolescente tem contribuído para as superlotações das unidades de internação. O gráfico já apresentado sinaliza como as unidades de Semiliberdade do interior estão com poucos jovens. Poderia, por exemplo, se privilegiar a Semiliberdade, com, inclusive, melhores possibilidades de redirecionamento social, em contato permanente com a família e a comunidade, favorecidos por essa medida socioeducativa.

Atrelado às situações supracitadas, tem-se todo um sistema de gestão do socioeducativo ineficiente, com contratações de pessoal e aquisição de bens e serviços feitos por meio de recursos financeiros administrados por intermédio de ONGs (Organizações Não Governamentais). Tais recursos não chegam adequadamente às unidades nem por meio das contratações nem por meio dos bens e serviços. Segundo os socioeducadores, o controle dos recursos sofre com pressões de interesses políticos externos, com uma relação promíscua entre Estado e privado, que faz que de todos os lados e dos mais diversos atores do sistema saiam afirmações de má utilização e até de desvio de recursos.

Desde a gestão do Sistema até o trabalho educativo, que deveria ser realizado tanto interno, quanto externo às unidades, observa-se o sucateamento, que agrava as violências e aproxima os jovens da criminalidade (CEDECA, 2016).

Esse contexto de instabilidade tem gerado rebeliões e ações constantes da Segurança Pública, por meio da força desproporcional da Polícia Militar dentro das unidades, decorrente, entre tantos outros motivos já sinalizados, de estratégias falhas dos gestores do Sistema Socioeducativo do Estado:

Fala 12 - socioeducador: Houve rebeliões em outras unidades, em que quebraram tudo, e então deram a ordem lá da Secretaria de transferir jovens para unidades que não estavam quebradas, sem qualquer tipo de critério. Não foi respeitado idade, tipo de delito, sentenciado ou provisório, perfil do jovem, etc. Isso foi equivocado demais, [...] e provocou paralização das atividades, medo nos socioeducadores, [...] e que gerou em dezembro, como se esperava, a rebelião nessa nossa unidade. No total, faz mais ou menos cinco meses que não têm absolutamente nada na unidade, sem condições necessárias para o andamento normal das atividades pedagógicas. [...] foram feitas reformas para a recuperação da estrutura, e nisso os garotos ficaram presos, recebendo apenas o básico e, agora em janeiro, que temos feito acompanhamento deles com psicólogos, assistentes sociais, pois tínhamos poucos profissionais e estamos pensando em estratégias para fazer funcionar as aulas, oficinas e atividades de esporte. Mas vale dizer que o contingente, já te disse isso várias vezes, é muito pequeno, então a casa vai funcionar no limite, talvez liberando uma ala de cada vez, [...]

\footnotetext{
5 A medida de Internação Provisória (45 dias improrrogáveis) deve ser utilizada nos casos de maior gravidade e em que essa forma de internação se mostra necessária para o bom andamento do processo, que, via de regra, resultará numa medida de internação. Quando já há previsão de que ao término dos 45 dias o adolescente será colocado em medida de meio aberto, a utilização da Internação Provisória é vista e utilizada por alguns juízes como forma de "castigo" para o adolescente, o que é considerado uma violação da lei e dos direitos do adolescente. De igual modo, o uso da medida de internação como forma de "proteção" para aqueles com acentuado uso abusivo de drogas, mas sem um ato infracional que justifique tal medida, é considerado no meio jurídico uma ilegalidade, mas aplicada por diversos juízes.
} 
teremos em torno de 20 meninos para administrar nas atividades. [...] se não iniciarmos, mesmo que aos poucos, nada vai funcionar. [...] eles estão ficando lá trancados e isso só piora as coisas, é como condicionar um comportamento de rebeldia, do jeito que está estamos produzindo monstros, [...] eles já queimaram nesses dias de janeiro os colchões que foram entregues. A situação não é nada tranquila, mas precisamos avançar, fazer funcionar a socioeducação, mesmo sem respaldo dos gestores do sistema socioeducativo do Ceará.

O encarceramento está intimamente relacionado com o modelo de gestão do Sistema Socioeducativo, pela insuficiência na qualidade administrativa:

- a contratação de funcionário ocorre independente das habilidades e capacidades para o trabalho com medidas socioeducativas. Há nos poucos funcionários que estão nas unidades, cansaço e desmotivação, sem saberem o que e como fazer. Disso, decorrem relatórios técnicos ignorados pelo Poder Judiciário, à vista de que esses relatórios são feitos de forma errônea e com informações que não favorecem os jovens. O resultado é que ao serem apreciados pelos técnicos do Ministério Público é pedida a permanência dos jovens na internação, respaldado pelo Poder Judiciário; trabalho socioeducativo fragmentado, pouco comprometimento e comunicação entre os funcionários, o que compromete o fluxo de atendimento e, consequentemente, a execução do trabalho;

- o suporte administrativo e de segurança tem produzido, atrelado ao contexto de conflitos e expressão de violência dos jovens, um evidente entrave na formação pedagógica dos atendidos;

- a ausência de trabalho integrado, sem gestão compartilhada com a rede de serviços do Município, revela as dificuldades de gerenciamento interno e externo à unidade, sobretudo tendo em vista a necessidade da intersetorialidade e da interinstitucionalidade, isto é, articulação entre os serviços de saúde, da educação, da assistência social, da cultura, que constituem o sistema socioeducativo. Do jeito atual, a unidade funciona precariamente como instituição total (GOFFMAN, 2008), em detrimento da participação e responsabilização socioeducativa do jovem no espaço público, conforme preconizado no SINASE e ECA;

- a transferência de jovens sem documentação e/ou relatório técnico, e/ou processo judicial. Tal situação é agravada ainda quando ocorre no período noturno, deixando os jovens sem nenhum tipo de recepção por parte da equipe técnica, e tão somente aos cuidados de socioeducadores. Essa decisão dos gestores do Sistema ocasiona desorganização, sobretudo na identificação dos jovens que estão em cumprimento de medida. Pode parecer absurdo, mas já ocorre em várias unidades, de não saberem quem são os jovens que ali se encontram e por qual ato infracional estão em cumprimento de medida socioeducativa.

Constata-se, a partir dessas descrições, observações e análises, que é difícil desenvolver profícuas ações educativas sem equipe gestora adequada e quando não há um sistema de serviços públicos do Município e do Estado trabalhando de modo articulado com a execução das medidas socioeducativas (FRANCISCO; MARTINS, 2017).

No atendimento diário dos jovens, perde-se de vista o que é fundamental e fundante para o Sistema: o cunho pedagógico planejado para a desinstitucionalização. 
Atrelado aos fatores negativos da educação vivenciada na internação, que não atende aos interesses da sociedade, as situações de conflitos se agravam quando ficam inviáveis as visitas das famílias de jovens que são do interior, pois as unidades foram construídas e estão concentradas na periferia de Fortaleza. Longe dos familiares, da comunidade em que cresceram, desprovidos de proteção, sem visitas por dias ou meses, esses jovens ficam mais estressados e agem pela violência.

A estratégia de logística, sobretudo em se tratando da construção e instalação das unidades, inviabiliza a convivência familiar e ocasiona superlotações. Pode-se compreender pelo Mapa 1, dados esses apenas de jovens de uma unidade, que os mesmos são provenientes de diferentes regiões do estado do Ceará.

Mapa 1 - Origem dos jovens internados em uma unidade de Fortaleza-CE.

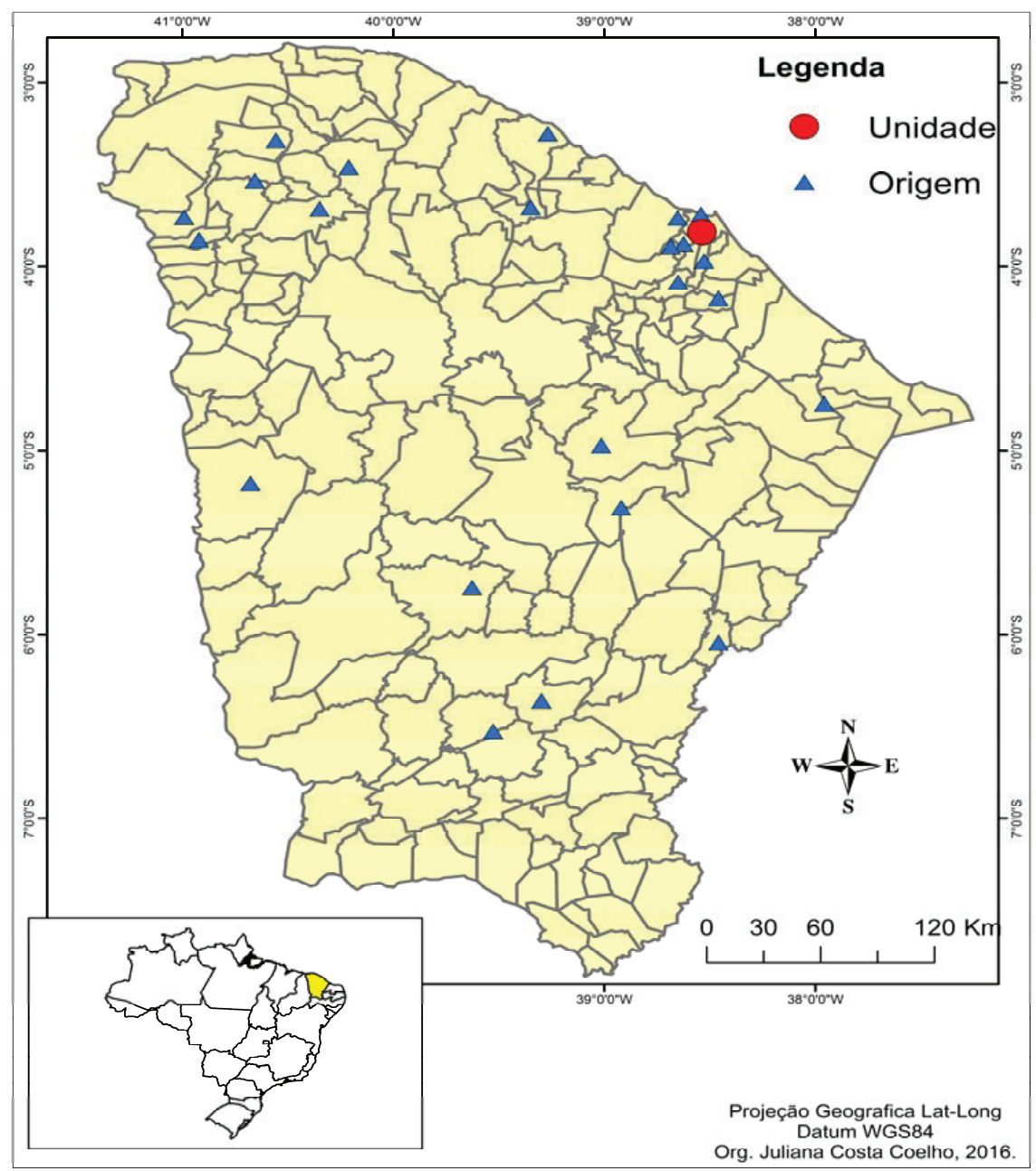

Fonte: Mapa produzido por Juliana Costa Coelho, 2017. 
Como pode se verificar, há uma série de problemas estratégicos na execução do Sistema Socioeducativo. No caso específico das instalações, poderia se minimizar essa falha com a descentralização das unidades, construindo unidades menores por macrorregiões no estado do Ceará, além de valorizar e incentivar as medidas de Liberdade Assistida e de Semiliberdade nos diferentes municípios, com maiores chances de obter resultados positivos no enfrentamento das infrações, à vista da maior facilidade da integração dos jovens com os serviços públicos disponíveis a que eles têm direito.

Em meio a essas situações, há toda uma ansiedade por parte de integrantes da comunidade, da instituição e de movimentos sociais, em viabilizar a transformação dessa realidade que se vive. A necessária mudança exige muito mais do que tão-somente vontade, mas engajamento e posição política de todos os responsáveis/instituições que atuam no Sistema Socioeducativo do Ceará.

Faz-se necessário pensar em formas educativas e estratégias de gestão pública humanizadas para enfrentar a situação de crise, avançando para uma perspectiva de educação em liberdade, de modo a romper as barreiras repressivas construídas, de tipo policialesca e que operam na desigualdade (LIMA; SINHORETTO; BUENO, 2015).

Reitera-se a urgência de um trabalho articulado que ocorra continuamente e atrelado a uma mesma filosofia educativa, desde a apreensão do adolescente e do jovem, até o trabalho de egresso, em caráter de formação continuada e de compromisso entre as áreas que integram o Sistema de Garantia de Direitos - SGD, de sustentação para um trabalho de qualidade e para a liberdade.

\section{CONSIDERaÇões FINAIS}

Insta reiterar que transformar os fundamentos repressivos do tradicional sistema prisional juvenil em curso significa também visualizar e implantar outro tipo de execução do sistema, que se quer socioeducativo. A atual fragilidade executiva ocasiona o isolamento e cria uma ruptura entre a realidade vivida nas unidades e a participação comunitária, na sociedade, reproduzindo inúmeras deficiências físicas, humanas, educativas, administrativas. Além de considerarmos a inadequação ao combate/criminalização das drogas, tido como caso de polícia e motivo de apreensão de inúmeros jovens imersos no comércio ilegal, o que tem gerado e reproduzido ainda mais superlotações, violências e fortalecimento das redes criminosas dentro e fora das unidades. Fatores esses, entre outros, que explicam os conflitos e a exclusão sistêmica de jovens, principalmente os que estão nos estratos das classes sociais subalternizadas.

Em decorrência disso, percebe-se que, embora a quantidade de controle e punição tenha aumentado na esfera da ação do Estado, o incentivo à prática delituosa não se reduz, ao contrário, há um agravamento dela.

Os jovens necessitam de atendimento que lhes proporcione segurança, mas não a Segurança Pública entendida na sua tradicional perspectiva seletiva, que opera na desigualdade, em decorrência dos interesses da propriedade e do capital. Segurança pública não 
é e não pode buscar a garantia da ordem pública pela violência sobre os estratos sociais "indesejáveis", os pobres e os negros das periferias deterioradas. Populações essas, diga-se de passagem, crescem e se desenvolvem num clima socializador impulsionado pela "ordem pública" das facções criminosas, num ciclo cultural nefasto - produtor de novos infratores.

Há de se efetivar outra perspectiva para a segurança, a educação e a justiça juvenil, que considere um trabalho integrado entre Polícia, Ministério Público e Poder Judiciário, que represente cidadania, participação comunitária e uma organização sistematizada e coerente na execução socioeducativa, principalmente no meio fechado. Para tanto, é preciso privilegiar relações de confiança e de responsabilidade nos jovens e com regras compactuadas para o bem coletivo, num processo de avaliação não autoritário nos relatórios técnicos dos profissionais executores das medidas socioeducativas, sobretudo dos socioeducadores, acompanhados e apoiados de perto pelas instituições de justiça.

O ponto de partida para a mudança é a própria prática social infracional, que deve fazer os sujeitos avançarem para um patamar de assimilação de conhecimentos e reflexão para outro agir, incentivados por possibilidades de envolvimento em atividades culturais e de trabalho na comunidade, avaliados e acompanhados colaborativamente em vista da mudança do curso da vida que gera violência. Logo, o ponto de chegada é a mudança de toda ação violenta que gera aprisionamento do corpo e das mentes.

Assim, em busca de ruptura com o modelo clássico repressivo-reprodutivista da Segurança Pública e seus desdobramentos no sistema socioeducativo, que cada vez mais se mostra ineficiente, enseja considerar um processo de desinstitucionalização do curso da juventude, que privilegie a responsabilização socioeducativa, quando do ato infracional, por meio de Liberdade Assistida, Prestação de Serviço à Comunidade e, nos casos graves, Semiliberdade.

A internação pode ser utilizada em último caso e, mesmo assim, se faz urgente fomentar projetos pedagógicos, mesmo no interior da unidade, que caminhem para a inserção social, isto é, aproximar os jovens de modo gradativo em atividades socioculturais em liberdade, próximos da família e da comunidade de origem.

De maneira preventiva, antes dos delitos, vale considerar um estudo biopsicossocial e acompanhamento das famílias em situação de vulnerabilidade social. Um trabalho emergencial de empenho entre os operadores de justiças, assistência social e secretarias de cultura, de educação e da infância e juventude dos municípios é imprescindível em vista de maior aproximação com esses grupos excluídos que se mostram expostos à delinquência, em prol de apoio e fortalecimento familiar, bem como inclusão dos jovens em políticas públicas de acesso e permanência na escola e no trabalho.

Destarte, enseja que haja um trabalho consistente e que a justiça e os direitos não sejam utopias subjetivistas, mas realidade no cotidiano das famílias de todo indivíduo, em busca de uma cultura de paz, num engajamento fundamental dos movimentos de luta pela igualdade, como exigência para a construção de outro tipo de socialização, mais digna, com potencial transformador das relações opressivas. 


\section{REFERÊNCIAS}

BARDIN, Laurence. Análise de Conteúdo. Lisboa - Portugal: Edições 70, 2010.

BECHER, Franciele. Os "menores" e a FUNABEM: influências da ditadura civil-militar brasileira. In: Simpósio Nacional de História. 1, 2011, São Paulo. Anais XXVI ANPUH. São Paulo: ANPUH, 2011, p. 1-16.

BOGDAN, Robert; BIKLEN, Sari. Investigação qualitativa em educação: uma introdução à teoria e aos métodos. Porto - Portugal: Porto Editora, 2010.

BRASIL, Lei 8.069, de 13 de julho de 1990. Estatuto da Criança e do Adolescente (ECA).

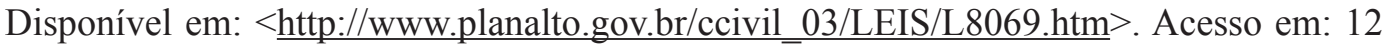
abr. 2017.

CALDEIRA, Tereza; HOLSTON, James. Democracy and violence in Brazil. Society for comparative studies. Society and History, v. 41, n. 4, p. 691-729, 1999.

CEDECA. Relatório de Inspeção Abril/Maio. Unidades de Internação do Sistema So-

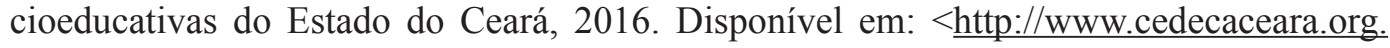
br/wp-content/uploads/2016/08/Relat $\% \mathrm{C} 3 \%$ B3rio-F\%C3\%B3rum-DCA-e-Defensoria-P\%C3\%BAblica.pdf $>$. Acesso: 12 abr. 2017.

CHIZZOTTI, Antonio. Pesquisa em ciências humanas e sociais, 4. ed. São Paulo-SP: Cortez, 2000.

COOMBS, Philip. La crisis mundial en la educación. Perspectivas Actuales. Madrid - EP. Santilhana, 1985.

CROSWELL, John W. Projeto de Pesquisa: métodos qualitativo, quantitativo e misto, 2. ed. Porto Alegre-RS: Artmed, 2007.

DEL PRIORI, Mary. O cotidiano da criança livre no Brasil entre a Colônia e o Império. In: Del Priori, Mary (Org.). História das Crianças no Brasil, 5. ed. São Paulo: Contexto, 2006, p. 84-106.

FALEIROS, Vicente de Paula. Infância e Adolescência: trabalhar, punir, educar, assistir, proteger. Revista ágora (Rio de Janeiro), Rio de Janeiro, v. 1, nº 1, 2004, p. 1-9.

FONSECA, Débora Cristina. Escolarização de adolescentes em privação de liberdade: análise do tema em uma amostra de periódicos. Revista Eletrônica de Educação. São Carlos, SP: UFSCar, v. 7, nº 1, p. 13-31, mai. 2013. Disponível em: <http://www.reveduc.ufscar. br>. Acesso em: 6 jun. 2017. 
FRANCISCO, Julio Cesar; MARTINS, Marcos Francisco. Adolescentes em privação de liberdade na Fundação CASA - Sorocaba/SP: ato infracional e processo educativo, 2014. Disponível em: <http://www.gpec.ucdb.br/serie-estudos/index.php/serie-estudos/article/view/741/665>. Acesso em: 6 jun. 2017.

FRANCISCO, Julio Cesar; MARTINS, Marcos Francisco. Perspectivas da Educação Não Escolar no Trato com Jovens Infratores. Educacao \& Realidade, Porto Alegre, v. 42, nº 1, jan./mar. 2017, p. 283-297.

FRONTANA, Isabel C. R. da Cunha. Crianças e adolescentes nas ruas de São Paulo. São Paulo: Loyola, 1999.

GAMBOA, Silvio Ancisar Sanchez. A dialética na pesquisa em educação: elementos de contexto. In FAZENDA, I. (Org.). Metodologia da pesquisa educacional, $11^{\mathrm{a}}$ Ed. São Paulo- SP: Cortez, 2008, p. 91-115.

GOFFMAN, Erving. Manicômios, prisões e conventos. Tradução: Dante Moreira Leite, $8^{\mathrm{a}}$ Ed. São Paulo-SP: Perspectiva, 2008.

IANNI, Octavio. A Sociedade Global. São Paulo: Civilização Brasileira, 1992.

LANCELLOTTI, Julio Renato. O menor e a igreja. São Paulo-SP: Revista São Paulo em Perspectiva, 1987.

LIBERATI, Wilson Donizeti. Adolescente e ato infracional: medida socioeducativa é pena? São Paulo-SP: Malheiros, 2012.

LIMA, Agnaldo Soares. Guia para implantação do atendimento inicial ao adolescente a quem se atribui autoria de ato infracional. Brasília-DF: Editora Dom Bosco, 2013.

LIMA, Sérgio de Lima; SINHORETTO, Jacqueline; BUENO, Samira. A gestão da vida e da segurança pública. Sociedade e Estado, Brasília, v. 30, p. 123-144, abr. 2015. Disponível em:

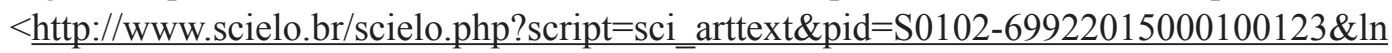
$\mathrm{g}=\mathrm{en} \& \mathrm{nrm}=\mathrm{iso}>$. Acesso em: 10 jun. 2017.

LÜDKE, Menga; ANDRÉ, Marli Eliza Dalmazo. Pesquisa em Educação: abordagens qualitativas. São Paulo-SP: EPU, 2012.

MASELLA, Marcio Alexandre. O Adolescente em Liberdade Assistida e sua Inserção na Rede Pública de Ensino de Embu/SP (2008/2009). Dissertação apresentada ao Programa de Pós-Graduação da Pontifícia Universidade Católica de São Paulo, 2010.

MAUAD, Ana Maria. A vida das crianças de elite durante o Império. In: Del Priori, Mary (Org.). História das Crianças no Brasil, 5. ed. São Paulo: Contexto, 2006, p. 137-176.

268 Comunicações | Piracicaba | v. $25 \mid$ n. $3 \mid$ p. $247-269 \mid$ set.-dez. 2018 
PASSETTI, Edson. Crianças carentes e políticas públicas. In: Del Priori, Mary (Org.). História das Crianças no Brasil, 5. ed. São Paulo: Contexto, 2006, p. 347-375.

PEREZ, José Roberto Rus; PASSONE, Eric Ferdinando. Políticas sociais de atendimento às crianças e aos adolescentes no Brasil. Cadernos de Pesquisa, v. 40, n. 140, 2010. Disponível em: $<$ http://www.scielo.br/pdf/cp/v40n140/a1740140.pdf $>$. Acesso em: 25 jun. 2017.

SILVA, Inez Maria de Jesus; SANTOS, Nadja Maria; MELO, Rosana Alves. Contexto de vida de adolescentes em período de reclusão. Rev. Multidisciplinar e de Psicologia, 2016. Disponível em: $<$ https://idonline.emnuvens.com.br/id/article/view/507/738>. Acesso em: 6 jun. 2017.

Agradecimentos especiais: ao CNPq (Conselho Nacional de Desenvolvimento Científico e Tecnológico) pelo apoio financeiro e ao Padre Agnaldo Soares Lima pela colaboração com a pesquisa.

\section{Dados dos Autores:}

\section{Julio Cesar Francisco}

Pedagogo, Mestre e Doutorando em Educação pela Universidade Federal de São Carlos. Bolsista da Fundação de Amparo à Pesquisa do Estado de São Paulo (2018 - Atual), ex-bolsista CNPq e CAPES. Consultor especializado em Sistema Socioeducativo. Endereço eletrônico: socioeducativo.julio@gmail.com

\section{Elenice Maria Cammarosano Onofre}

Docente do Programa de Pós-Graduação em Educação da Universidade Federal de São Carlos - UFSCar. Coordenadora do EduCárceres - Núcleo de Investigação e Práticas em Educação nos Espaços de Restrição e Privação de Liberdade /UFSCar. Endereço eletrônico: linocam@uol.com.br

Submetido em: 3-9-2017

Aceito em: 12-6-2018 